\title{
Chronic diuretic therapy attenuates renal BOLD magnetic resonance response to an acute furosemide stimulus
}

Michael E Hall ${ }^{1}$, Michael V Rocco ${ }^{2,8}$, Timothy M Morgan ${ }^{3,8}$, Craig A Hamilton ${ }^{4,8}$, Matthew S Edwards ${ }^{5,8}$, Jennifer H Jordan ${ }^{6,8}$, Justin B Hurie, ${ }^{5,8}$ and W Gregory Hundley $6,7,8^{*}$

\begin{abstract}
Background: Blood Oxygen Level Dependent (BOLD) magnetic resonance (MR) is a novel imaging tool that detects changes in tissue oxygenation. Increases in renal oxygenation in response to a standard 20 mg intravenous furosemide stimulus have been evaluated to assess kidney viability in patients with renal artery stenosis (RAS). The effect of prior exposure to furosemide on the ability of BOLD MR techniques to evaluate renal function is unknown. This study tested the hypothesis that chronic loop diuretic therapy is associated with attenuated responses in renal tissue oxygenation as measured by BOLD MR with an acute $20 \mathrm{mg}$ intravenous furosemide stimulus in participants undergoing evaluation for RAS.
\end{abstract}

Methods: Thirty-eight participants referred for evaluation of RAS were recruited for this study. We examined renal cortical and medullary BOLD signal $\left(T 2^{*}\right)$ intensities before and after a $20 \mathrm{mg}$ intravenous furosemide stimulus. Additionally, we measured changes in renal artery blood flow using phase contrast techniques.

Results: After controlling for covariates age, race, gender, diabetes, glomerular filtration rate, body mass index, and stenosis severity, daily oral furosemide dose was an independent, negative predictor of renal medullary T2* response $(p=0.01)$ to a standard $20 \mathrm{mg}$ intravenous furosemide stimulus. Stenosis severity and ethnicity were also significant independent predictors of changes in $\mathrm{T} 2^{*}$ signal intensity in response to an acute furosemide challenge. Changes in renal blood flow in response to acute furosemide administration were correlated with changes in $T 2^{*}$ in the renal cortex $(r=0.29, p=0.03)$ but not the medulla suggesting changes in renal medullary oxygenation were not due to reduced renal medullary blood flow.

Conclusions: Chronic furosemide therapy attenuates BOLD MR responses to an acute furosemide stimulus in patients with RAS being evaluated for renal artery revascularization procedures. Thus, patients who are chronically administered loop diuretics may need a different dosing strategy to accurately detect changes in renal oxygenation with BOLD MR in response to a furosemide stimulus.

Keywords: Renal BOLD, Oxygenation, Furosemide, Renal artery stenosis

\footnotetext{
* Correspondence: ghundley@wakehealth.edu

${ }^{6}$ Department of Medicine, Section on Cardiology, Wake Forest University

School of Medicine, Winston-Salem, USA

'Department of Radiology, Wake Forest University School of Medicine,

Winston-Salem, USA

Full list of author information is available at the end of the article
} 


\section{Background}

Improvement in renal tissue oxygenation manifested by increased Blood Oxygen Level Dependent (BOLD) magnetic resonance (MR) signal intensity after intravenous (IV) furosemide has recently been identified as a potential noninvasive marker of "renal viability" that may indicate kidneys most suitable for renal artery revascularization procedures [1,2]. In these MR procedures, BOLD images are generally acquired prior to and fifteen minutes after a standard IV $20 \mathrm{mg}$ dose of furosemide [1-3]. If a kidney subtended by a renal arterial luminal narrowing $\geq 70 \%$ is unable to increase tissue oxygenation in response to an IV $20 \mathrm{mg}$ furosemide stimulus, it may be less likely to significantly improve its function after renal artery revascularization (as evidenced by reduction in systemic arterial pressure and increased glomerular filtration rate [GFR]).

Importantly however, the potential influence of chronic oral furosemide treatment on the response to an acute furosemide stimulus during the BOLD MR imaging procedure is unknown. This point is important because patients with severe renal artery stenosis (RAS) receiving chronic loop diuretic therapy may have an attenuated BOLD MR response to acute furosemide administration. If this is the case, an attenuated BOLD MR response to furosemide could incorrectly be interpreted as evidence that the patient might not benefit from renal artery revascularization procedures when in fact they may be a suitable candidate. In this study, we prospectively evaluated renal cortical and medullary BOLD MR measures before and after $20 \mathrm{mg}$ of IV furosemide in patients aged $\geq$ 55 years who were referred for RAS evaluation. We examined the BOLD MR responses to $20 \mathrm{mg}$ of IV furosemide after accounting for the chronic administration of oral loop diuretic therapy.

\section{Methods}

\section{Study population}

This study was approved by the Institutional Review Board (IRB) at the Wake Forest School of Medicine and all study participants provided written, witnessed informed consent. We included 38 participants referred for evaluation of RAS based on existing clinical suspicion or findings from existing non-invasive imaging studies including renal Doppler examinations, contrast angiography or CT. Participants were ineligible for enrollment if they exhibited a contraindication for MR (implanted metal, pacemakers, defibrillators, other electronic devices or claustrophobia), active acute coronary or cerebral or peripheral arterial symptoms, severe aortic stenosis or other significant valvular disease, or those with a contraindication to the receipt of furosemide. After enrollment, GFR was estimated in each participant using the Chronic Kidney Disease Epidemiology Collaboration (CKD-EPI) equation [4] using the serum creatinine value obtained from a blood draw obtained within four weeks prior to each MR examination. Participants were asked to abstain from taking any diuretics including furosemide at least 12 hours prior to the MR scan. The records and clinical characteristics of each participant were reviewed in accordance with Wake Forest School of Medicine IRB policies.

\section{MR Imaging protocol}

Comprehensive MR imaging examinations were performed on a Magnetom Avanto 1.5 Tesla scanner (Siemens Medical Solutions USA, Malvern, Pennsylvania) using a phased-array surface coil applied across the abdomen to optimize signal to noise. Electrocardiographic (ECG) leads and respiratory gating bellows were applied to account for cardiac and respiratory motion respectively. Blood pressure and heart rate were monitored periodically during the MR examination to ensure hemodynamic stability.

A three-dimensional (3D), segmented steady-state free-precession sequence with non-selective radiofrequency excitation was utilized to acquire non-contrasted angiograms of the renal arteries. The fields of view (FOV) ranged from $30-40 \mathrm{~cm}$ to cover the entire abdomen in the axial position to obtain 3D volume acquisitions. Imaging parameters included a repetition time (TR) of $2.3 \mathrm{~ms}$, an echo time (TE) of $1 \mathrm{~ms}$, a $90^{\circ} \mathrm{flip}$ angle, a readout bandwidth of $980 \mathrm{~Hz}$ per pixel, a $256 \times$ 256 matrix, and a total of approximately $40-503 \mathrm{D}$ partitions with a slice thickness of $3 \mathrm{~mm}$. A parallel imaging technique, generalized autocalibrating partially parallel acquisition (GRAPPA) with an acceleration factor of 2 was applied to shorten scan times. Percentage stenosis of each renal artery was visually estimated by a blinded board-certified cardiologist and cardiovascular imager.

After locating the renal arteries, an image series of the vessels in double-obliqued cross-sectional orientation was obtained to ensure a circular lumen throughout the cardiac cycle to minimize partial volume effects during image acquisition. Interleaved, phase-contrast gradientecho sequences were used to determine cardiac cycledependent measurements of vessel area and velocity according to previously published techniques from our laboratory [5]. These sequences were positioned in an oblique plane $2 \mathrm{~cm}$ distal to the origin of the renal artery at the aorta. These scans utilized $7 \mathrm{~mm}$ thick slices with a $256 \times 256$ matrix, $32 \mathrm{~cm}$ FOV (yielding voxel sizes of $0.94 \times 0.94 \times 7 \mathrm{~mm}$ for the renal artery), a $40^{\circ}$ flip angle, a TR of $11 \mathrm{~ms}$, and a TE of $3.5 \mathrm{~ms}$.

During suspended respiration, three-plane, single-shot, fast spin-echo localizing images of the kidneys were performed followed by additional scout images oriented parallel to the coronal axis of each kidney [2]. BOLD imaging consisted of a 2-D fast spoiled gradient echo 
sequence with eight echoes (TE's ranged from 2.5$30 \mathrm{~ms}$ ) obtained at each slice location. BOLD imaging parameters included a slice thickness of $10 \mathrm{~mm}$, a $224 \times$ 160-192 imaging matrix, a $32-40 \mathrm{~cm}$ FOV, a $45^{\circ}$ flip angle, and a TR of $140 \mathrm{~ms}$ [6]. The FOV was adjusted based on participants' body sizes and the imaging matrix and TR's were adjusted in participants with diminished breath hold capabilities.

BOLD images were acquired during suspended respiration with coronal slices through the middle of each kidney. Signal intensity versus TE data on a voxel by voxel basis were used to generate parametric images of $\mathrm{T} 2 \%$. After completion of the initial BOLD acquisitions, each participant received $20 \mathrm{mg}$ IV furosemide according to previously published methods [1,2]. Fifteen minutes after receipt of furosemide, the renal arterial flow (phase contrast) and T2* (BOLD) acquisitions were repeated.

After acquisition, images were transferred to a postprocessing station for analysis. A single person blinded to clinical participant characteristics performed all image analyses. Images (either BOLD or phase contrast) were excluded if there was severe motion artifact, bowel gas artifacts or if image quality was degraded and renal segments (cortex versus medulla) or renal artery were not able to be clearly identified. Phase contrast and BOLD images were analyzed using post-processing in custom-written MATLAB (The Mathworks, Inc.; Natick, Massachusetts). The cross-sectional area of the renal arterial lumen was defined on the magnitude image of the reference scan by a region of interest (ROI) which was then superimposed on the velocity map for each corresponding frame of the cardiac cycle and the mean velocities were obtained by measuring the average pixel intensity within the ROI.

Renal cortical and medullary $\mathrm{T} 2 \%$ values were determined by manually tracing ROI's on arterial spin labeling images with the highest corticomedullary differentiation. Each ROI contained at least 5 voxels. These ROI's were then copied onto the corresponding parametric T2* maps (both pre-and post-furosemide). Care was taken to ensure that the ROI was drawn in clearly identifiable cortical or medullary segments. Areas of artifact or cysts were avoided. These same ROI's were then copied onto the post-furosemide images to ensure similar segmental position within each kidney.

\section{Statistical analysis}

All statistical analyses were performed using SAS 9.2 software (SAS Institute, Cary, North Carolina). Subjects were classified into two groups: chronic furosemide therapy versus furosemide naïve. The dosage of chronic furosemide therapy was also considered as a continuous covariate. Descriptive statistics were performed on participants on chronic furosemide therapy and compared to furosemide naïve participants. A p-value of $<0.05$ was considered to be statistically significant. Univariate, multivariable, and backwards stepwise regression analyses using mixed model procedures, with kidney side and kidney region considered as repeated measures, were performed to evaluate the effect of kidney region, age, gender, ethnicity, estimated GFR, stenosis severity, presence of diabetes, body mass index, use of ACEI/ARBs, number of antihypertensive medications, and chronic daily furosemide dose (total daily dose in $\mathrm{mg}$ ) on changes in renal tissue oxygenation as measured by percentage change in $\mathrm{T}^{*}$ signal intensities before and after $20 \mathrm{mg}$ IV furosemide administration. Similar statistical models were used to evaluate the effects of these variables on percentage changes in main RBF with kidney side as the only repeated measure. Percentage change in RBF was determined using the change in the measured flow from the pre-furosemide image to the postfurosemide image divided by the pre-furosemide (baseline) measurement. The correlation between percentage changes in RBF using phase contrast and percentage change in renal tissue oxygenation $(\mathrm{T} 2 *)$ was estimated using Pearson's correlation coefficient separately within each kidney region.

\section{Results}

A total of 38 participants were evaluated in this study. Descriptive statistics of the participants, subdivided by the concurrent use of chronic furosemide therapy are displayed in Table 1. Participants receiving chronic furosemide therapy exhibited lower GFR's $(p=0.005)$, required more antihypertensive medications $(p=0.0001)$, were more likely to be diabetic $(\mathrm{p}=0.01)$, and were less commonly treated with angiotensin converting enzyme (ACE) inhibitors or angiotensin receptor blockers (ARBs, $\mathrm{p}=0.006$ ). Among the 15 participants chronically administered furosemide, the total daily dose range ranged from $20 \mathrm{mg}$ daily to $160 \mathrm{mg}$ daily.

\section{Effect of chronic furosemide therapy on $\mathrm{T}^{*}$ response to acute furosemide administration}

Representative MR scans of participants who were or were not receiving chronic furosemide therapy are shown in Figure 1. Overall, furosemide naïve participants experienced significant increases in cortical $\mathrm{T} 2 *$ values after the $20 \mathrm{mg}$ IV furosemide stimulus whereas those receiving chronic furosemide did not (Figure 2). Both furosemide naïve and recipients of chronic oral furosemide experienced an increase in renal medullary $\mathrm{T} 2 \%$ signal intensities after the $20 \mathrm{mg}$ IV furosemide stimulus albeit with a strong trend toward attenuation of the response in those chronically prescribed oral furosemide $(\mathrm{p}=0.07)$.

Using repeated measures multiple regression analyses, change in total kidney oxygenation ( $\mathrm{T} 2{ }^{*}$ ) was univariately 
Table 1 Participant characteristics

\begin{tabular}{|c|c|c|c|}
\hline \multirow[t]{2}{*}{ Participant characteristics } & \multirow{2}{*}{$\begin{array}{c}\begin{array}{c}\text { Furosemide } \\
\text { naïve }\end{array} \\
(n=23)\end{array}$} & \multirow{2}{*}{$\begin{array}{c}\begin{array}{c}\text { Chronic } \\
\text { furosemide }\end{array} \\
(n=15)\end{array}$} & \multirow[t]{2}{*}{ p-value } \\
\hline & & & \\
\hline Age (years) & $68 \pm 8$ & $69 \pm 10$ & 0.49 \\
\hline Race & & & 0.28 \\
\hline White (\%) & 78 & 67 & \\
\hline African American (\%) & 22 & 33 & \\
\hline Gender (\% male) & 35 & 40 & 0.65 \\
\hline Body mass index $\left(\mathrm{kg} / \mathrm{m}^{2}\right)$ & $29.4 \pm 6.5$ & $30.3 \pm 7.1$ & 0.56 \\
\hline GFR (mL/min/1.73 $\left.\mathrm{m}^{2}\right)$ & $60.1 \pm 31.6$ & $44.6 \pm 14.7$ & $0.005^{*}$ \\
\hline \multicolumn{4}{|l|}{ Renal artery stenosis (mean,\%) } \\
\hline Left & 26 & 24 & 0.70 \\
\hline Right & 26 & 21 & 0.82 \\
\hline \multicolumn{4}{|l|}{ Renal blood flow (mean, $\mathrm{ml} / \mathrm{min}$ ) } \\
\hline Left & 187 & 127 & 0.17 \\
\hline Right & 231 & 196 & 0.50 \\
\hline Chronic kidney disease stage (n) & & & $0.01^{*}$ \\
\hline Stage 1 (GFR > 90) & $5(22 \%)$ & $0(0 \%)$ & \\
\hline Stage 2 (GFR 60-89) & $5(22 \%)$ & $2(13 \%)$ & \\
\hline Stage 3 (GFR 30-59) & $9(39 \%)$ & $9(60 \%)$ & \\
\hline Stage 4 (GFR 15-29) & $4(17 \%)$ & $4(27 \%)$ & \\
\hline Stage $5(G F R<15)$ & $0(0 \%)$ & $0(0 \%)$ & \\
\hline Hypertension diagnosis (\%) & 91 & 100 & 0.25 \\
\hline $\begin{array}{l}\text { Number of antihypertensive } \\
\text { meds ( } n \text { ) }\end{array}$ & $2.7 \pm 1.6$ & $4.3 \pm 1.0$ & $0.0001^{*}$ \\
\hline Hemoglobin (g/dL) & $12.7 \pm 2.3$ & $12.1 \pm 1.8$ & 0.25 \\
\hline Diabetes diagnosis (\%) & 30 & 60 & $0.01^{*}$ \\
\hline Patients on statin therapy (\%) & 65 & 73 & 0.45 \\
\hline Patients on ACEl's or ARB's (\%) & 65 & 33 & $0.006^{*}$ \\
\hline
\end{tabular}

Mean \pm SE are displayed. GFR glomerular filtration rate, $A C E I$ angiotensin converting enzyme inhibitors, $A R B$ angiotensin receptor blockers. *represents $p<0.05$.

predicted by kidney region (cortex versus medulla, $\beta=-3.76 \pm 1.81, p=0.04)$ and chronic daily furosemide dose $(\beta=-0.06 \pm 0.03, p=0.04)$. Multivariable analyses demonstrated significant negative effects for both region $(\beta=-4.06 \pm 1.89, \mathrm{p}=0.04)$ and chronic furosemide dose $(\beta=-0.08 \pm 0.03, \mathrm{p}=0.02)$ after accounting for age, GFR, gender, BMI, percentage stenosis of the renal artery, diagnosis of diabetes, use of ACE inhibitors/ARBs, and number of antihypertensive medications. There were no significant interaction effects between the variables kidney region (cortex vs medulla) and total daily furosemide dose or GFR and furosemide dose.

There was a significant difference in the GFR's of the two groups $(p=0.01)$. Therefore, we performed analyses after excluding the five participants with high normal renal function $\left(G F R \geq 90 \mathrm{~mL} / \mathrm{min} / 1.73 \mathrm{~m}^{2}\right.$ ) in order to make the groups more comparable. Kidney region (cortex vs medulla, $\beta=-4.23 \pm 1.96, \mathrm{p}=0.04$ ) and total daily furosemide dose $(\beta=-0.06 \pm 0.03, p=0.04)$ remained as significant predictors of attenuated T2* signal intensity changes in response to an acute furosemide stimulus.

Due to the significant effect of kidney region on T2* changes in response to acute furosemide administration, we also evaluated covariates within each region of the kidney. Univariate and backwards stepwise regression analyses were performed (Table 2). Using backwards stepwise regression, three variables (ethnicity $[\mathrm{p}=0.004]$, stenosis severity $[\mathrm{p}=0.04$, and chronic daily furosemide dose $[\mathrm{p}=0.01]$ ) were significant independent predictors of changes in $\mathrm{T} 2$ * signal intensity in response to an acute furosemide stimulus. The results of our model indicate that a patient receiving $40 \mathrm{mg}$ of furosemide twice daily or $80 \mathrm{mg}$ once daily would be predicted to exhibit a $9 \%$ attenuation of the $\mathrm{T} 2 *$ signal intensity response in the renal medulla to a $20 \mathrm{mg}$ IV furosemide stimulus, assuming no differences in the other variables. The association between receipt of higher chronic daily doses of furosemide and attenuated renal medullary $\mathrm{T} 2 *$ signal intensity changes in response to a $20 \mathrm{mg}$ IV furosemide stimulus nearly reached statistical significance $(r=-0.19$, $\mathrm{p}=0.08$, Figure 3 ).

\section{Renal artery blood flow response to acute furosemide}

Renal artery blood flow (RBF) was measured before and after acute $20 \mathrm{mg}$ IV furosemide administration using phase contrast techniques in the main renal artery. Baseline RBF was lower, although not statistically significant, in participants chronically administered oral furosemide compared to furosemide naïve participants $(160 \pm 14 \mathrm{ml} / \mathrm{min}$ vs. $210 \pm 27 \mathrm{ml} / \mathrm{min}, \mathrm{p}=0.11$ ). This reduction in baseline RBF was independent of stenosis severity as there was no difference in stenosis severity between the two groups $(\mathrm{p}=0.69)$. RBF increased to $238 \pm 28 \mathrm{ml} / \mathrm{min}(\mathrm{p}=0.005)$ in furosemide naïve participants. RBF did not significantly increase from pre to post-furosemide measures in participants chronically receiving daily oral doses of furosemide $(165 \pm 16 \mathrm{ml} / \mathrm{min}, \mathrm{p}=0.37)$. Changes in RBF were moderately correlated with changes in cortical $\mathrm{T}^{*}$ values (Figure $4, \mathrm{r}=0.29, \mathrm{p}=0.03$ ). There was no significant correlation between changes in RBF and changes in renal medullary $\mathrm{T} 2 *(\mathrm{r}=0.04, \mathrm{p}=0.74)$.

\section{Discussion}

The results of this study indicate that chronic oral furosemide administration attenuates the increase in renal medullary oxygenation in response to an acute $20 \mathrm{mg}$ IV furosemide stimulus measured by BOLD MR, that higher daily doses of furosemide are associated with reduced increases in the medullary BOLD responses to a standard furosemide challenge, and that changes in RBF 


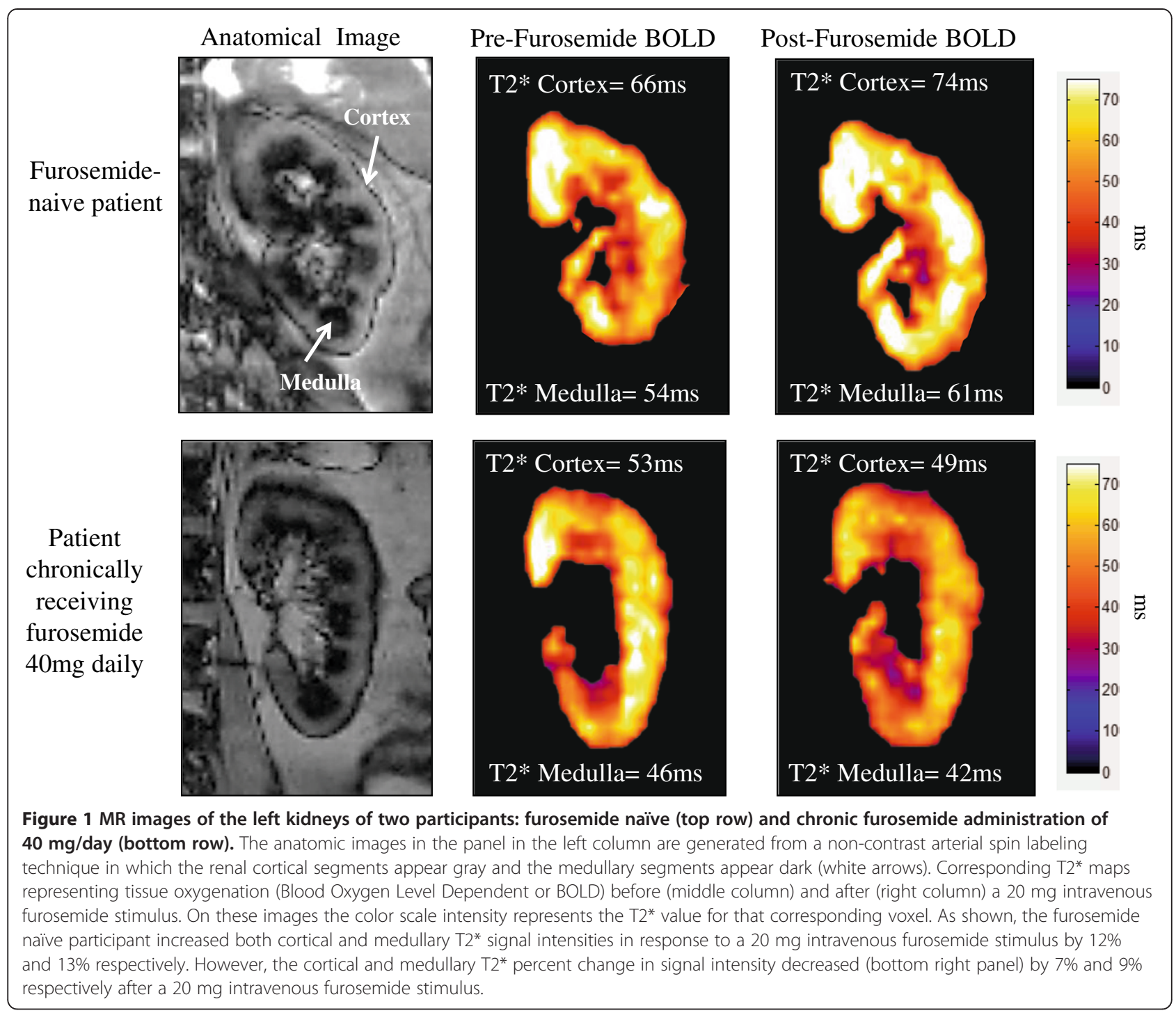

are correlated with changes in renal tissue oxygenation in the cortex but not in the medulla.

Renal artery stenosis is a complex pathophysiologic process that can result in malignant hypertension (HTN), renal dysfunction and exacerbation of congestive heart failure [7-9]. Renal artery revascularization procedures, either surgical or percutaneous, have been utilized to treat renovascular HTN in patients with malignant HTN, declining renal function, or those who develop pulmonary edema based on current guideline recommendations [10]. However, less than half of patients who undergo these revascularization procedures actually receive significant clinical benefit defined as improvement in renal function and GFR, or blood pressure [7]. To date, ideal strategies to identify patients who will derive a benefit from renal artery revascularization procedures remain elusive.

Recently, BOLD MR imaging has been evaluated as a potential tool to determine if a kidney with a renal artery lesion can increase oxygenation in response to a $20 \mathrm{mg}$ IV furosemide stimulus [1,2]. Small cross-sectional studies suggest that a kidney with the ability to improve tissue oxygenation (manifested by an increase in BOLD signal intensity) in response to a furosemide stimulus may be more likely to benefit from a revascularization procedure $[1,2,11]$. Furosemide, a loop diuretic, blocks transport of the sodium-potassium-2chloride ( $\mathrm{Na}-\mathrm{K}-2 \mathrm{Cl})$ transporter located in the thick ascending limb of the loop of Henle (TALH) within the renal medulla [12]. Luminal $\mathrm{Na}+$ uptake via the apical membrane $\mathrm{Na}-\mathrm{K}-2 \mathrm{Cl}$ transporter is coupled to basolateral membrane transport which depends on Na-K-ATPase activity, an oxygen $\left(\mathrm{O}_{2}\right)$-dependent process $[13,14]$. Therefore, blocking the $\mathrm{Na}-\mathrm{K}-2 \mathrm{Cl}$ transporter reduces renal medullary $\mathrm{O}_{2}$ consumption and increases tissue oxygenation.

Since many patients with severe renovascular disease require loop diuretics to prevent hypervolemia, it is 


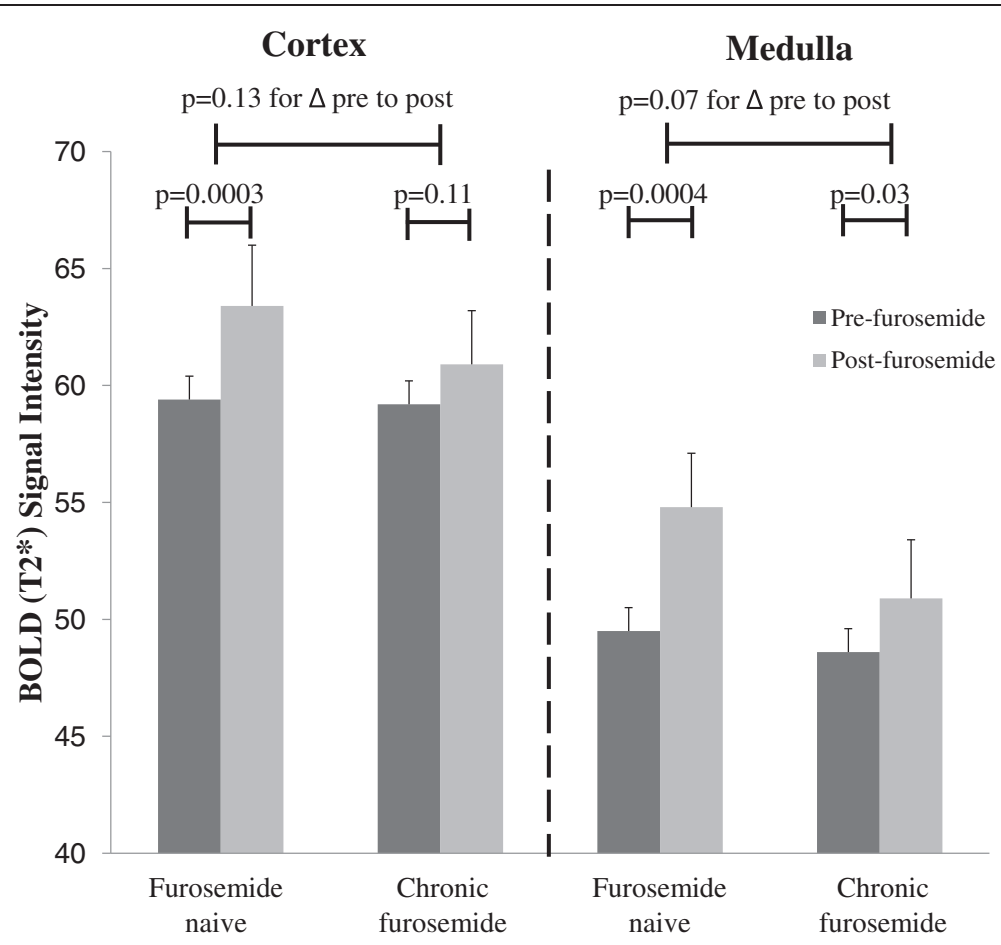

Figure 2 Bar graph displaying mean \pm SE renal cortical and medullary BOLD signal intensities (T2*) prior to (light gray) and after (black) a $20 \mathrm{mg}$ intravenous furosemide stimulus in furosemide naïve participants compared with participants chronically receiving furosemide.

important to determine the effect of chronic loop diuretic use on the BOLD MR response to an acute stimulus with furosemide. Otherwise, patients receiving chronic loop diuretic therapy who demonstrate attenuated increases in $\mathrm{T}_{2}^{*}$ signal intensities after acute furosemide administration may be inappropriately deemed less likely to receive clinical benefit from renal artery revascularization procedures. Our results demonstrate that chronic oral furosemide consumption is associated with attenuated increases in medullary oxygenation after $20 \mathrm{mg}$ of IV furosemide (Figure 2) despite abstaining from furosemide ingestion greater than 12 hours prior to BOLD MR examination. The half-life of furosemide is 30 to 60 minutes, therefore 12 hours should be more than adequate time to withhold furosemide. The results of our model indicate that a patient receiving $40 \mathrm{mg}$ of furosemide twice daily or $80 \mathrm{mg}$ once daily would be predicted to exhibit nearly a $10 \%$ attenuation of the $\mathrm{T} 2$ \% signal intensity response in the renal medulla to a $20 \mathrm{mg}$ IV furosemide stimulus, assuming no differences in the other variables.

Despite worsened renal dysfunction and a higher prevalence of diabetes in the chronic furosemide group, pre-furosemide cortical and medullary $\mathrm{T} 2 *$ values were similar to furosemide naïve participants. This observation illustrates the point that unless patients have a critical renal arterial narrowing, the renal cortex and medulla are able to maintain tissue oxygenation, at least
Table 2 Univariate and backwards stepwise regression analyses of percentage change in renal medullary tissue oxygenation ( $\mathrm{T} 2 *$ signal intensity) in response to a $20 \mathrm{mg}$ intravenous furosemide stimulus

\begin{tabular}{|c|c|c|c|c|}
\hline \multirow[t]{2}{*}{ Variables } & \multicolumn{2}{|c|}{ Univariate } & \multicolumn{2}{|c|}{$\begin{array}{l}\text { Backwards stepwise } \\
\text { regression }\end{array}$} \\
\hline & $\begin{array}{l}\text { Parameter } \\
\text { estimate (SE) }\end{array}$ & p-value & $\begin{array}{l}\text { Parameter } \\
\text { estimate (SE) }\end{array}$ & p-value \\
\hline Age & $0.32(0.29)$ & 0.28 & & \\
\hline $\begin{array}{l}\text { Glomerular filtration } \\
\text { rate }\end{array}$ & $0.05(0.11)$ & 0.65 & & \\
\hline Gender & $2.27(4.31)$ & 0.61 & & \\
\hline Ethnicity & $-14.4(4.61)$ & $0.006^{*}$ & $-13.1(4.09)$ & $0.004^{*}$ \\
\hline Stenosis severity (\%) & $-0.12(0.06)$ & $0.04^{*}$ & $-0.11(0.05)$ & $0.04^{*}$ \\
\hline Diabetes diagnosis & $0.72(4.61)$ & 0.88 & & \\
\hline Body mass index & $-0.49(0.33)$ & 0.15 & & \\
\hline $\begin{array}{l}\text { Chronic daily } \\
\text { furosemide dose } \\
\text { (mg/day) }\end{array}$ & $-0.09(0.05)$ & 0.09 & $-0.11(0.04)$ & $0.01^{*}$ \\
\hline ACEI/ARB use & $6.41(4.64)$ & 0.18 & & \\
\hline $\begin{array}{l}\text { Antihypertensive } \\
\text { medications (number) }\end{array}$ & $0.98(1.74)$ & 0.58 & & \\
\hline
\end{tabular}




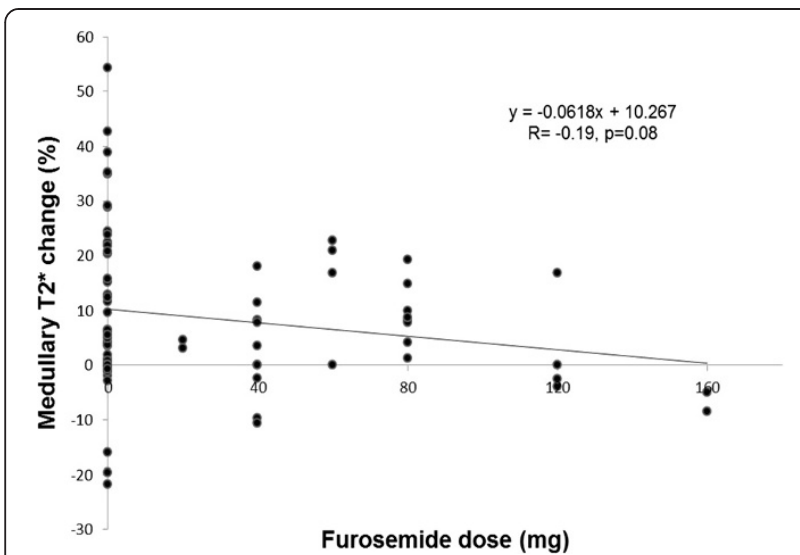

Figure 3 Scatter plot demonstrating the relationship between daily oral furosemide dose (x-axis) and the percentage change in medullary $\mathrm{T}^{*}$ values after $\mathbf{2 0} \mathrm{mg}$ intravenous furosemide (y-axis). The circular symbols $(\bullet)$ represent data from a single participant. The regression equation and line are displayed. The asterisk ${ }^{*}$ ) represents $p<0.05$.

at rest. However, upon a $20 \mathrm{mg}$ IV furosemide challenge, participants receiving chronic furosemide did not significantly increase $\mathrm{T}^{*}$ signal intensities in the cortex. Although these participants did exhibit a significant increase in T2* signal intensities after $20 \mathrm{mg}$ IV furosemide in the renal medulla compared to pre-furosemide values, they exhibited attenuated increases in medullary $\mathrm{T} 2 *$ values compared to furosemide naïve participants (Figure 4).

After adjustment for covariates age, gender, race, GFR, diabetes, stenosis severity and BMI, number of antihypertensive medications, use of ACE inhibitors or ARBs, chronic daily furosemide dose was a significant negative predictor of the renal medullary $\mathrm{T} 2 *$ response to an acute furosemide stimulus. Although it did not quite meet statistical significance $(p=0.07)$ due to a relatively small number of participants in this study, total daily furosemide dose was associated with attenuated $\mathrm{T} 2 *$ signal intensity changes in response to an acute furosemide stimulus. However, chronic daily furosemide dose did not predict the response in the cortex. This finding is consistent with the site of action of loop diuretics such as furosemide which act on the TALH [15]. In rodents, furosemide significantly increased $\mathrm{O}_{2}$ levels measured by $\mathrm{O}_{2}$-sensitive electrodes in the renal medulla [16]. This increase in medullary oxygenation was due to decreased tubular $\mathrm{O}_{2}$ consumption as medullary blood flow was decreased by nearly $30 \%$.

White race was also associated with significantly attenuated T2* responses in the medulla to an acute furosemide stimulus. Textor et al. found higher baseline BOLD MR renal medullary R2* values (inverse of $\mathrm{T}^{*}$ ) in African Americans, compared to whites [17]. After a furosemide stimulus, however, these R2* levels decreased to the same values as in whites. These findings suggest increased $\mathrm{O}_{2}$ consumption and TALH $\mathrm{Na}+$ reabsorption in African Americans compared to whites. If whites reabsorb less $\mathrm{Na}+$ in the TALH, they would be expected to have less inhibition of the $\mathrm{Na}-\mathrm{K}-2 \mathrm{Cl}$ transporter in response to furosemide. Therefore, our findings corroborate those of Textor et al. suggesting that African Americans have increased $\mathrm{Na}+$ reabsorption in the TALH compared to whites. The mechanisms involved in the augmented TALH $\mathrm{Na}+$ reabsorption in African Americans are poorly understood and warrant further study.

Higher chronic furosemide doses were associated, albeit weakly, with attenuated $\mathrm{T} 2 \%$ responses to an acute

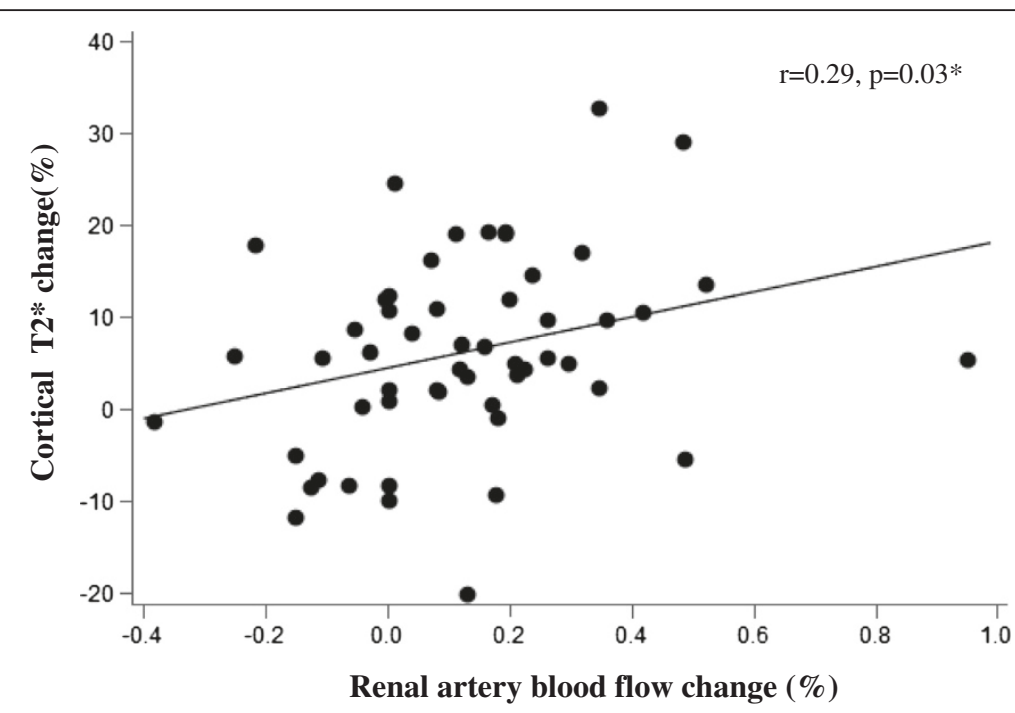

Figure 4 Scatter plot demonstrating the relationship between percentage change in renal artery blood flow and percentage change in renal cortical T2* values (x-axis) after $20 \mathrm{mg}$ intravenous furosemide (y-axis). The regression line, Pearson's correlation coefficient, and p-value are displayed. 
furosemide stimulus. Although this association was not statistically significant, it would likely achieve significance with a larger study size. This finding is intuitive, given that with most classes of medications, higher chronic daily doses reflect altered pharmacokinetics requiring higher acute doses to achieve a desired physiologic response.

Renal tissue oxygenation is at least partly dependent on oxygen delivery via RBF $[18,19]$. One limitation of many studies evaluating renal oxygenation with BOLD $M R$ is the reliance on either iodinated or gadolinium based contrast administration for determination of RBF. The former would require a separate imaging examination (computed tomography [CT]), possibly introducing different physiological conditions at separate time points. While RBF and perfusion can be determined during one single imaging examination with the administration of gadolinium contrast, this agent is contraindicated in patients with GFR $<30 \mathrm{ml} / \mathrm{min} / 1.73 \mathrm{~m}^{2}$ due to the risk of nephrogenic systemic fibrosis [20], thereby limiting the potential application of this diagnostic strategy in individuals with progressed renal dysfunction.

We employed phase contrast techniques to quantify RBF in each renal artery before and after IV furosemide to determine whether $\mathrm{RBF}$ influenced $\mathrm{O}_{2}$ utilization. In furosemide naïve participants, $\mathrm{RBF}$ increased in response to $20 \mathrm{mg}$ IV furosemide suggesting vasodilation which has been reported previously in human studies [21]. In participants chronically administered furosemide, RBF tended to be lower at baseline and did not increase after $20 \mathrm{mg}$ IV furosemide. This may reflect the higher prevalence of diabetes and/or renal insufficiency in these participants. There was no difference in the severity of stenoses between the two groups.

Change in cortical $\mathrm{T} 2 *$ intensity was correlated with RBF measures, while there was no correlation observed in the medulla. Compared to the cortex, the medulla receives much less blood flow relative to its high metabolic workload and functions in near-hypoxic conditions at baseline [22,23]. Therefore, alterations in RBF and subsequently $\mathrm{O}_{2}$ delivery should be better tolerated in the cortex due to its abundance of blood flow [24]. Our findings suggest that the increase in tissue oxygenation observed in the cortex is likely related to increases in total $\mathrm{RBF}$ and $\mathrm{O}_{2}$ delivery, at least in those not receiving chronic furosemide therapy. However, we observed increases in medullary tissue oxygenation in response to an acute furosemide stimulus although this response was reduced compared to those not receiving chronic furosemide. The relationship between RBF and oxygenation is complex, particularly in the medulla. Increases in $\mathrm{RBF}$ do increase renal $\mathrm{O}_{2}$ delivery; however, increases in $\mathrm{RBF}$ also increase tubular $\mathrm{Na}+$ delivery and transport resulting in increased metabolic workload [25]. Our observations may reflect compensatory mechanisms in the medulla to maintain homeostasis and potentially downregulate non-essential metabolic functions in times of reduced $\mathrm{RBF}$ and $\mathrm{O}_{2}$ delivery that may occur with renal arterial stenoses. Alternatively, RBF may be shunted towards the medulla during stress conditions to maintain metabolic demands as the cortex is relatively overperfused and is likely able to better tolerate reductions in total RBF compared to the medulla. Hence, there is no significant correlation between total RBF and renal medullary oxygenation unless $\mathrm{RBF}$ is reduced below a critical point which may be observed in severe renal arterial narrowings.

Our study has some limitations. We were unable to obtain measurements of renal oxygenation by BOLD in 6 of the 76 kidneys due to artifacts (motion or bowel gas) and poor image quality. RBF measures were not performed in 12 of the 76 renal arteries due to inadequate visualization of the renal artery on phase contrast velocity maps due to extremely low blood flow or motion artifact. Second, $\mathrm{Na}+$ intake or reabsorption and water loading conditions were not monitored in our study and could potentially confound our results. Another potential confounder is the higher prevalence of participants on ACE inhibitors or ARBs in the furosemide naïve group. We attempted to adjust for these factors in our multivariable analyses. Although these agents theoretically may influence renal tissue oxygenation [26], they did not increase renal issue oxygenation in type 2 diabetic hypertensive patients in a recent study using BOLD MR imaging with a furosemide stimulus [3]. Because the GFRs were different between our two groups, we performed additional analyses with exclusion of five of the furosemide naïve group with GFR $>90$ to try to minimize some of the between group differences which and the same variables (ethnicity, stenosis severity and chronic daily furosemide dose) remained as significant independent predictors of changes in $\mathrm{T} 2 *$ intensity in response to an acute furosemide stimulus. Our findings are consistent with findings published in a study of 280 patients demonstrating no differences in $\mathrm{T} 2 \%$ intensities between different stages of CKD [27]. However, our findings build upon this work by demonstrating no relationship of GFR to changes in $\mathrm{T}^{*}$ signal intensities in response to an acute furosemide stimulus. Because many of these factors are closely linked, future studies specifically aimed at determining the effects of chronic furosemide therapy on acute $\mathrm{T} 2 *$ responses to a furosemide stimulus should be evaluated in better matched cohorts, possibly with differing doses of furosemide stimuli. It would be reasonable to investigate administering a larger intravenous dose of furosemide comparable to the chronic furosemide dose that patients' receive chronically to be able to detect an appropriate increase in renal oxygenation before determining if a kidney downstream from a severe 
renal artery stenosis would benefit from a revascularization procedure.

\section{Conclusions}

Our study demonstrates that chronic furosemide therapy attenuates BOLD MR responses to an acute furosemide stimulus in patients with RAS being evaluated for renal artery revascularization procedures. If BOLD MR with a furosemide stimulus becomes a more widely used method for determining clinical outcomes for these procedures, careful attention should be paid to evaluating results in those receiving chronic loop diuretic therapy. Our findings suggest that patients on chronic loop diuretic therapy may require different doses of IV furosemide as a stimulus to detect changes in renal tissue oxygenation and blood flow before BOLD MR is widely used to determine renal viability.

\section{Competing interests}

This study was funded in part by NIH grant R42 AG030248, a Small Business Initiative Grant award to Prova, Inc for which Dr. Hundley and Dr. Hamilton are minor stock holders. All other authors had no disclosures to report.

\section{Authors' contributions}

$\mathrm{MH}$ was involved in scan data acquisition, image analysis, data/statistical analyses, interpretation of data, and drafting the manuscript. MR was involved in study design, interpretation of data, and editing the manuscript. TM was involved in study design, statistical analyses, and editing the manuscript. CH was involved in study design, image acquisition and analyses, interpretation of data and editing the manuscript. ME was involved with study design, patient recruitment, interpretation of data, and editing the manuscript. JJ was involved with image analysis, interpretation of data, and editing the manuscript. JH was involved with patient recruitment and editing the manuscript. WGH was involved with study design, image acquisition and analysis/interpretation, and editing the manuscript. All authors read and approved the final manuscript.

\section{Authors' information}

WGH is the senior and corresponding author of this manuscript.

\section{Acknowledgements}

This work was supported in part by the following National Institutes of Health Grants: R42 AG030248 (Hundley), R01 HL076438-02 (Hundley), and P30 AG21332 (Hundley).

The authors express their gratitude to the study participants, the MR technologists (Jenny Hagee, Jennifer McGuinn, Timothy Ratcliffe, Meredith Gammons), and to the study coordinator Crosby Moss. Preliminary data from this project was presented as a poster presentation at the Society of Cardiovascular Magnetic Resonance Meeting in San Francisco, California in January 2013.

\section{Author details}

${ }^{1}$ Department of Medicine, Division of Cardiology, University of Mississippi Medical Center, Jackson, Mississippi, USA. ${ }^{2}$ Department of Medicine, Section on Nephrology, Wake Forest University School of Medicine, Winston-Salem, USA. ${ }^{3}$ Department of Biostatistical Sciences, Wake Forest University School of Medicine, Winston-Salem, USA. ${ }^{4}$ Department of Biomedical Engineering, Wake Forest University School of Medicine, Winston-Salem, USA. ${ }^{5}$ Department of Vascular Surgery, Wake Forest University School of Medicine, Winston-Salem, USA. ${ }^{6}$ Department of Medicine, Section on Cardiology, Wake Forest University School of Medicine, Winston-Salem, USA. 'Department of Radiology, Wake Forest University School of Medicine, Winston-Salem, USA. ${ }^{8}$ Wake Forest School of Medicine, Medical Center Boulevard, Winston-Salem, NC 27157-1045, USA.

Received: 24 September 2013 Accepted: 29 January 2014 Published: 3 February 2014

\section{References}

1. Textor S, Glockner J, Lerman L, Misra S, McKusick MA, Reiderer SJ, Grade JP, Gomez SI, Romero JC. The use of magnetic resonance to evaluate tissue oxygenation in renal artery stenosis. J Am Soc Nephrol. 2008; 19:780-8.

2. Gloviczki ML, Glockner JF, Lerman LO, McKusick MA, Mistra S, Grande JP, Textor SC. Preserved oxygenation despite reduced blood flow in poststenotic kidneys in human atherosclerotic renal artery stenosis. Hypertension. 2010; 55:961-6.

3. Pruijim M, Hofmann L, Zanchi A, Maillard M, Forni V, Muller ME, Wuezner G, Vogt B, Stuber M, Burnier M. Blockade of the renin-angiotensin system and renal tissue oxygenation as measured with BOLD-MRI in patients with type 2 diabetes. Diabetes Res Clin Pract. 2013; 99:136-44.

4. Levey AS, Stevens LA, Schmid CH, Zhang YL, Castro AF 3rd, Feldman HI, Kusek JW, Eggers P, Van Lente F, Greene T, Coresh J. CKD-EPI (Chronic Kidney Disease Epidemiology Collaboration). A new equation to estimate glomerular filtration rate. Ann Intern Med. 2009; 150:604-12.

5. Hundley WG, Li F, Willard JE, Landau C, Lange RA, Meshack BM, Hillis LD, Peshock RM. Magnetic resonance imaging assessment of the severity of mitral regurgitation: comparison of invasive techniques. Circulation. 1995; 92:1151-8.

6. Gloviczki ML, Glockner J, Gomez SI, Romero JC, Lerman LO, McKusick M, Textor SC. Comparison of 1.5 and 3T BOLD MR to study oxygenation of kidney cortex and medulla in human renovascular disease. Invest Radiol. 2009; 44:566-71.

7. Conlon PJ, O'Riordan E, Kalra PA. New insights into the epidemiologic and clinical manifestations of atherosclerotic renovascular disease. Amer J of Kidney Dis. 2000; 35:573-87.

8. Caps MT, Perissinotto C, Zierler R, Polissar NL, Bergelin RO, Tullis MJ, CantwellGab K, Davidson RC, Strandness DE Jr. Prospective study of atherosclerotic disease progression in the renal artery. Circulation. 1998; 98:2866.

9. Textor SC. Atherosclerotic renal artery stenosis: overtreated but underrated? J Am Soc Nephrol. 2008; 19:656-9.

10. Hirsch AT, Haskal ZJ, Hertzer NR, Bakal CW, Creager MA, Halperin JL, Hiratzka LF, Murphy WR, Olin JW, Puschett JB, Rosenfield KA, Sacks D, Stanley JC, Taylor LM Jr, White CJ, White J, White RA, Antman EM, Smith SC Jr, Adams $C D$, Anderson JL, Faxon DP, Fuster V, Gibbons RJ, Halperin JL, Hiratzka LF, Hunt SA, Jacobs AK, Nishimura R, Ornato JP, Page RL, Riegel B. ACC/AHA 2005 guidelines for the management of patients with peripheral arterial disease (lower extremity, renal, mesenteric, and abdominal aortic): executive summary a collaborative report from the American Association for Vascular Surgery/Society for Vascular Surgery, Society for Cardiovascular Angiography and Interventions, Society for Vascular Medicine and Biology, Society of Interventional Radiology, and the ACC/ AHA Task Force on Practice Guidelines (Writing Committee to Develop Guidelines for the Management of Patients With Peripheral Arterial Disease) endorsed by the American Association of Cardiovascular and Pulmonary Rehabilitation; National Heart, Lung, and Blood Institute; Society for Vascular Nursing; TransAtlantic Inter-Society Consensus; and Vascular Disease Foundation. J Am Coll Cardiol. 2006; 47:1239-312.

11. Gloviczki ML, Lerman LO, Textor SC. Blood oxygen level-dependent (BOLD) MRI in renovascular hypertension. Curr Hypertens Rep. 2011; 13:370-7.

12. Kokko JP. Site and mechanism of action of diuretics. Am J Med. 1984; 77:11-7.

13. Takahashi N, Kondo Y, Fujiwara I, Ito O, Igarashi Y, Abe K. Characterization of $\mathrm{Na}+$ transport across the cell membranes of the ascending thin limb of Henle's loop. Kidney Int. 1995; 47:789-94.

14. Eveloff J, Bayerdorffer E, Silva P, Kinne R. Sodium-chloride transport in the thick ascending limb of Henle's loop. Oxygen consumption studies in isolated cells. Pflugers Arch. 1981; 389:263-70.

15. Suki W, Rector FC, Seldin DW. The site of action of furosemide and other sulfonamide diuretics in the dog. J Clin Invest. 1965; 44:1458-69.

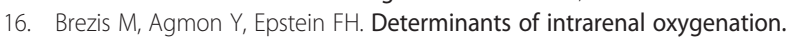
Effects of diuretics. Am J Physiol. 1994; 267:F1059-62.

17. Textor SC, Gloviczki ML, Flessner MF, Calhoun DA, Glockner J, Grande JP, McKusick MA, Cha SS, Lerman LO. Association of filtered sodium load with medullary volumes and medullary hypoxia in hypertensive African Americans as compared with whites. Am J Kidney Dis. 2012; 59:229-37.

18. Brezis M, Heyman SN, Epstein FH. Determinants of intrarenal oxygenation. II. Hemodynamic effects. Am J Physiol. 1994; 267:F1063-8.

19. Evans RG, Goddard D, Eppel GA, O'Connor PM. Factors that render the kidney susceptible to tissue hypoxia in hypoxemia. Am J Physiol Regul Integr Comp Physiol. 2011; 300:R931-40. 
20. Yang L, Krefting I, Gorovets A, Marzella L, Kaiser J, Boucher R, Rieves D. Nephrogenic systemic fibrosis and class labeling of gadolinium-based contrast agents by the food and Drug Administration. Radiology. 2012; 265:248-53.

21. Dormans T, Pickkers P, Russel F, Smits P. Vascular effects of loop diuretics. Cardiovasc Res. 1996; 32:988-97.

22. Brezis M, Rosen S. Hypoxia of the renal medulla: its implications for disease. N Engl J Med. 1995; 332:647-55.

23. O'Connor PM. Renal oxygen delivery: matching delivery to metabolic demand. Clin Exp Pharmacol Physiol. 2006; 33:961-7.

24. Epstein FH. Oxygen and renal metabolism. Kidney Int. 1997; 51:381-5.

25. Evans RG, Gardiner BS, Smith DW, O'Connor PM. Intrarenal oxygenation: unique challenges and the biophysical basis of homeostasis. Am J Physiol Regul Integr Comp Physiol. 2008; 295:F1259-70.

26. Deng A, Tang T, Singh P, Satriano J, Thomson SC, Blantz RC. Regulation of oxygen utilization by angiotensin II in chronic kidney disease. Kidney Int. 2009; 75:197-204.

27. Michaely HJ, Metzger L, Haneder, Hansmann J, Schoenberg SO, Attenberger UI. Renal BOLD-MRI does not reflect renal function in chronic kidney disease. Kidney Int. 2012; 81:684-9.

doi:10.1186/1532-429X-16-17

Cite this article as: Hall et al:: Chronic diuretic therapy attenuates renal BOLD magnetic resonance response to an acute furosemide stimulus. Journal of Cardiovascular Magnetic Resonance 2014 16:17.

\section{Submit your next manuscript to BioMed Central and take full advantage of:}

- Convenient online submission

- Thorough peer review

- No space constraints or color figure charges

- Immediate publication on acceptance

- Inclusion in PubMed, CAS, Scopus and Google Scholar

- Research which is freely available for redistribution 